\title{
EPIDEMIOLOGICAL TRENDS IN DIGESTIVE CANCERS IN ROMANIA, 1955-2012, COMPARED TO ALCOHOL CONSUMPTION. CORRELATION OR COINCIDENCE?
}

\author{
SIMONA VALEAN, ROMEO CHIRA, DAN DUMITRASCU
}

\author{
Iuliu Hatieganu University of Medicine and Pharmacy, Cluj-Napoca, Romania; \\ County Emergency Clinical Hospital Cluj-Napoca, Romania
}

\begin{abstract}
Background and aims. Cancer has emerged as the leading cause of death in human populations. The contribution of alcohol has been highly suspected. The purpose of this paper was to analyze the time trend of digestive cancers in Romania, in terms of mortality rates (1955-2012), and incidence rates (2008-2012), and the alcohol consumption data (1961-2010), aiming to find out if there is any association.

Methods. The data on six more common digestive cancers mortality rates (19552012) and incidence rates (2008-2012) were obtained from the historical and recent country statistics and publications of International Agency for Research on Cancer (IARC)/World Health Organisation (WHO), as age-standardized rate expressed per 100,000 population $(A S R w)$. Data on alcohol consumption were obtained from the statistics and publications of WHO and United European Gastroenterology (UEG), as liters of pure alcoholyear.

Results. Between 1955-2012, the ASRw of mortality registered an increase of the cancers of the esophagus in $M$ (from 2.03 to 3.90), and of colorectal cancer in both sexes (from 4.65 to 18.20 in M, and from 4.57 to 9.70 in F). Between 1980-2012, an increasing trend of mortality was registered, in both sexes, for the cancers of the pancreas (from 5.50 to 9.30 in $M$ and from 2.92 to 5.10 in F) and liver (from 1.77 to 11.00 , in $M$, and from 0.83 to 4.20 in F). In terms of incidence, between 2008-20012, an increasing trend of ASRw was registered for the cancers of the esophagus in $M$ (from 3.90 to 4.30), gastric cancer in $M$ (from 15.90 to 16.30), colorectal cancer in both sexes (from 27.60 to 34.50 in $M$ and from 19.00 to 20.20 in $F$ ), pancreatic cancer in $F$ (form 5.20 to 5.90), and liver cancer in $M$ (from 8.10 to 9.20). Alcohol consumption per capita (liters pure alcoholyear) increased in the

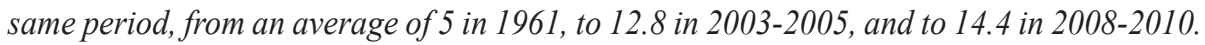

Conclusions. Given the parallel increase of some digestive cancers and alcohol consumption registered in our area, alcohol could represent more than a coincidence.
\end{abstract}

Keywords: alcohol behavior, digestive cancers, risk factor, time trend

\section{Background and aims}

Cancer has emerged as the leading cause of death in human populations [1-3]. Epidemiological studies emphasized the role of life style and of environmental factors in promoting the risk for digestive cancers. The contribution of alcohol was highly suspected. Even for digestive cancers with dominant infection etiology, like liver cancer and gastric cancer, the contribution of alcohol should be assessed. At population level there is a need to compare trends in epidemiological data of gastrointestinal cancers and data on alcohol consumption, in order to

Manuscript received: 16.05.2018

Received in revised form: 29.07.2018

Accepted: 29.08.2018

Address for correspondence: ioan.chira@umfcluj.ro extrapolate any causative relationship.

Digestive cancers, taken together, predominated as incidence and mortality rates, worldwide [4,5]. In 2012 , six cancers represented $55 \%$ of the global incidence burden, and three of them were digestive cancers, namely colorectal, stomach and liver cancers [6]. Care for digestive malignancies remained apparently suboptimal, as compared to other cancers [1,7-10].

The relative role of lifestyle vs environmental vs host factors as causes of cancer continued to be intensively studied [11]. Migrant studies suggested the role of environmental factors in promoting the risk for different diseases, including digestive cancers $[1,12]$. The role of infection was confirmed for certain digestive cancers [13]. Life style was also involved 
in oncogenesis. Alcohol is an oncogene [14]. Alcohol consumption, in terms of quantity and quality, could be a contributory risk factor to the development of preneoplastic lesions at the level of the digestive tract and, eventually, to digestive cancers, by indirect and direct effects [15-18]. Individual predisposition and genetics of cancers represent the most recent evaluations used for the estimation of the final mechanisms of the diseases [12]. Alcohol consumption increased in recent decades worldwide, also in Romania, where the alcohol consumption is one of the highest in the world, according to WHO estimates [16].

Given that the incidence of most digestive cancers changed in the last decades as well, we looked for the association between alcohol consumption and digestive cancers. We analyzed the total data and also the gender differences. The purpose of this paper is to analyze the time trend of digestive cancers in Romania, in terms of mortality rates (between 1955-2012), and incidence rates (between 2008-2012), in males (M) and females (F), in association with the time trend in alcohol consumption (between 1961-2010).

\section{Materials and methods}

The data on six more common digestive cancers mortality rates (1955-2012) and incidence rates (20082012) in $\mathrm{M}$ and $\mathrm{F}$, were obtained from the historical and recent country statistics and publications of IARC/ WHO, as ASRw (age-standardized rate expressed per 100,000 population, World Standard Population) (Tables I-III) [19-24]. The six cancers studied were: esophageal, gastric, colorectal, pancreatic, hepatic, gallbladder. Data on alcohol consumption were obtained from the statistics and publications of WHO [16] and UEG [17], as liters of pure alcohol/year. We compared the curves of evolution of most common digestive cancers during this time span with the evolution of alcohol consumption in the same country and time interval. We selected these data sources because they are reliable and open access. Some of the previous digestive cancer observatory studies for our country were also based on country statistics and publications of IARC/ WHO/Globocan [25-28] and represented local reports.

\section{Results}

Mortality rates, for the cancers of the esophagus, stomach, colon and rectum, were available for a period of 57 years (1955-2012). Mortality rates for the cancers of the pancreas and liver were available for 32 years (19802012), and those of the gallbladder for 22 years (from 1990 to 2012). The incidence rates of the all six digestive cancers were available for 2008 and 2012. Even often truncated, they offered the possibility to compose a picture of the time trend evolution of digestive cancers in our country (Table I) [19-24], and to analyze some particular aspects, such as the rate of the increase/decrease/sex (Table II) [19-24], and the recent evolution in incidence/sex (Table III) [23,24]. For the most recent period of estimation, the year 2012, the mortality-to-incidence ratio (M:I ratio) and the $\mathrm{M} / \mathrm{F}$ ratio of incidence were calculated (Table IV) [24]. Data on alcohol consumption in Romania (Table V) were available for three periods of time (1961, 2003-2005, and 2008-2010), between 1961 and 2010 [16,17].

Esophageal cancer registered an inconstant, but slow increase, only in males (Tables I, II). In 2012, it was the 5th digestive cancer as incidence and mortality in males, and the 6th in females. (Table III). The M:I ratio was high, second only to liver cancer (Table IV). The M/F ratio of mortality highly increased, from $3.27 / 1$ in $1955-59$, to $7.80 / 1$, in 2012 (Table I). M/F ratio of incidence was 8.60/1 in 2012, the highest among digestive cancers (Table IV).

Gastric cancer (GC) mortality registered a constant decrease in both sexes, higher in F (Tables I, II). Between 2008-2012, an increase in incidence was registered in $\mathrm{M}$ (Table III). In 2012, GC was still the 2nd digestive malignancy as incidence and the $2^{\text {nd }}$ cause of mortality from digestive cancer in $\mathrm{M}$, and the $3^{\text {rd }}$ in F (Table III). The M:I ratio was higher only as compared only to CRC and gallbladder cancer (Table IV). The M/F ratio of mortality increased, from 1.76/1 in $1955-59$, to $2.82 / 1$ in 2012 (Table I). The M/F ratio of incidence was 2.81/1, in 2012 (Table IV).

Colorectal cancer (CRC) has emerged as the most frequent digestive malignancy in 2012, as incidence and mortality from digestive cancer (Table III), after a long time of constant increase (Tables I-II]. In the same time, it had the lowest M:I ratio (of 0.52 in $\mathrm{M}$ and of 0.48 in F) (Table IV). The M/F ratio of mortality increased, from $1.01 / 1$ in $1955-59$, to $1.87 / 1$ in 2012 (Table I). The M/F ratio of incidence was of 1.70/1, in 2012 (Table IV).

Pancreatic cancer also registered a constant increase (Tables I, II). In 2012, it was the $3^{\text {rd }}$ digestive cancer as incidence, and the $4^{\text {th }}$ digestive cancer as cause of mortality in $\mathrm{M}$. In F, it was the 2 nd digestive cancer as incidence and the $3^{\text {rd }}$ cause of deaths from digestive cancer (Table III). The M:I ratio was high, being surpassed only by the mortality rates of liver and esophageal cancer (Table IV). The $\mathrm{M} / \mathrm{F}$ ratio of mortality registered some decrease, from $1.88 / 1$ in $1980-84$, to $1.82 / 1$ in 2012 (Table I). The M/F ratio of incidence was 1.74/1, in 2012 (Table IV).

Liver cancer registered the highest rate of increase of mortality (Tables I,II). In 2012, it was the $4^{\text {th }}$ digestive cancer an incidence, but the 3rd digestive cancer as a cause of mortality (Table III). The mortality exceeded the incidence rates in 2012 (Table IV). The M/F ratio of mortality slightly increased, from 2.13/1 in 1980-84, to 2.61/1 in 2012 (Table I). The M/F ratio of incidence was of 3.06/1, in 2012 (Table IV).

Gallbladder incidence and mortality rates were apparently more stable in the period of observation, of 22 years (Tables I,II). In 2012, it was the $6^{\text {th }}$ digestive cancer as incidence and mortality, in males. In females, it was the $5^{\text {th }}$ digestive cancer as incidence and mortality. In females, only esophageal cancer was more rarely recorded as incidence (Table III). The M:I ratio was higher only 
as regard to CRC (Table IV). The $\mathrm{M} / \mathrm{F}$ ratio of mortality decreased, from 1.14/1 in 1990-94, to 1/1 in 2012 (Table I). $\mathrm{M} / \mathrm{F}$ ratio of incidence was $1 / 1$ in 2012 (Table IV).

Alcohol consumption per capita registered a historical increase in Romania (as estimated by the
Global report on alcohol and health - 2014 ed. Country profile: Romania, page:232) (Table V) [16]. The recorded/ unrecorded alcohol consumption per capita $(15+$, in liters of pure alcohol) was estimated at average 8.8/4 in 20032005 and at 10.4/4 in 2008-2010) [16].

Table I. Digestive cancers in Romania - mortality rate time trends 1955-2012, in males and females (ASRw) [19-24].

\begin{tabular}{|l|l|l|l|l|l|l|}
\hline Year & Esophagus & Stomach & Colon \& rectum & Pancreas & Liver & Gallbladder \\
\hline $1955-59[19]$ & $2.03 / 0.62$ & $33.14 / 18.77$ & $4.65 / 4,57$ & & & \\
\hline $1960-64[19]$ & $1.86 / 0.58$ & $37.26 / 20.29$ & $6.10 / 6.02$ & & & \\
\hline $1965-69[19]$ & $1.96 / 0.51$ & $32.61 / 16.32$ & $8.61 / 5.55$ & & & \\
\hline $1970-74[19]$ & $1.75 / 0.56$ & $30.06 / 13,92$ & $6.59 / 6.20$ & & & \\
\hline $1974-79[19]$ & $1.65 / 0.52$ & $27.65 / 12.56$ & $7.45 / 6.46$ & & & \\
\hline $1980-84[19]$ & $1.56 / 0.43$ & $22.36 / 9.39$ & $8.65 / 6.84$ & $5.50 / 2.92$ & $1.77 / 0.83$ & \\
\hline $1985-89[20]$ & $1.70 / 0.40$ & $19.40 / 7.70$ & $9.60 / 7.30$ & $6.00 / 3.10$ & $2.01 / 1.00$ & \\
\hline $1990-92[21]$ & $1.80 / 0.40$ & $17.70 / 7.00$ & $10.10 / 7.40$ & $6.40 / 3.20$ & $3.30 / 1.50$ & \\
\hline $1990-94[22]$ & $2.04 / 0.41$ & $17.81 / 6,91$ & $10.56 / 7.59$ & $6.61 / 3.31$ & $4.34 / 1.99$ & $1.26 / 1.10$ \\
\hline $2008[23]$ & $3.50 / 0.40$ & $15.20 / 5.40$ & $16.70 / 9.70$ & $9.40 / 4.70$ & $10.50 / 4.00$ & $1.20 / 1.10$ \\
\hline $2012[24]$ & $3.90 / 0.50$ & $13.00 / 4.60$ & $18.20 / 9.70$ & $9.30 / 5.10$ & $11.00 / 4.20$ & $1.10 / 1.10$ \\
\hline
\end{tabular}

Table II. Digestive cancers in Romania - mortality rate time trends 1955-2012, in males and females (ASRw), and the rate of increase/ decrease [19-24].

\begin{tabular}{|l|l|l|l|l|l|l|}
\hline & Esophagus & Stomach & Colon \& rectum & Pancreas & Liver & Gallbladder \\
\hline Years & $1955-2012$ & $1955-2012$ & $1955-2012$ & $1980-2012$ & $1980-2012$ & $1990-2012$ \\
\hline Mortality rate M/F & $2.03 / 0.62-$ & $33.14 / 18.77-$ & $4.65 / 4.57-$ & $5.50 / 2.92-$ & $1.77 / 0.83-$ & $1.26 / 1.10-$ \\
& $3.90 / 0.50$ & $13.00 / 4.60$ & $18.20 / 9.70$ & $9.30 / 5.10$ & $11.00 / 4.20$ & $1.10 / 1.10$ \\
\hline Rate of increase/Decrease & & & & & & \\
\hline Males & +1.92 & -2.54 & +3.97 & +1.89 & +6.21 & -1.14 \\
\hline Females & $-! .24$ & -4.08 & +2.12 & +1.74 & +5.06 & 1 \\
\hline
\end{tabular}

Table III. Digestive cancers in Romania - incidence and mortality rates in males and females (ASRw), in 2008 and 2012 [23,24].

\begin{tabular}{|l|l|l|l|l|l|l|l|l|}
\hline Cancer & $\mathbf{2 0 0 8}$ & & & & $\mathbf{2 0 1 2}$ & & \\
\hline & Incidence & & Mortality & & Incidence & & Mortality & \\
\hline & $\mathrm{M}$ & $\mathrm{F}$ & $\mathrm{M}$ & $\mathrm{F}$ & $\mathrm{M}$ & $\mathrm{F}$ & $\mathrm{M}$ \\
\hline Esophagus & 3.90 & 0.50 & 3.50 & 0.40 & 4.30 & 0.50 & 3.90 & F \\
\hline Stomach & 15.90 & 5.80 & 15.20 & 5.40 & 16.30 & 5.80 & 13.00 & 4.60 \\
\hline Colon \& rectum & 27.60 & 19.00 & 16.70 & 9.70 & 34.50 & 20.20 & 18.20 & 9.70 \\
\hline Pancreas & 10.30 & 5.20 & 9.40 & 4.70 & 10.30 & 5.90 & 9.30 & 5.10 \\
\hline Liver & 8.10 & 3.00 & 10.50 & 4.00 & 9.20 & 3.00 & 11.00 & 4.20 \\
\hline Gallbladder & 1.70 & 1.60 & 1.20 & 1.10 & 1.50 & 1.50 & & 1.10 \\
\hline
\end{tabular}

Table IV. Digestive cancers in Romania - incidence, mortality, M/F ratio of incidence, and mortality-to-incidence ratio, 2012 [24].

\begin{tabular}{|l|l|l|l|l|l|l|}
\hline Cancer & Incidence & & Mortality & & M/F ratio of incidence & M:I ratio \\
\hline & $\mathrm{M}$ & $\mathrm{F}$ & $\mathrm{M}$ & $\mathrm{F}$ & & \\
\hline Esophagus & 4.30 & 0.50 & 3.90 & 0.50 & $8.60 / 1$ & M: $0.90 \mathrm{~F}: 1.00$ \\
\hline Stomach & 16.30 & 5.80 & 13.00 & 4.60 & $2.81 / 1$ & M: $0.79 \mathrm{~F}: 0.79$ \\
\hline Colon \& rectum & 34.50 & 20.20 & 18.20 & 9.70 & $1.70 / 1$ & M: $0.52 \mathrm{~F}: 0.48$ \\
\hline Pancreas & 10.30 & 5.90 & 9.30 & 5.10 & $1.74 / 1$ & M: $0.90 \mathrm{~F}: 0.86$ \\
\hline Liver & 9.20 & 3.00 & 11.00 & 4.20 & $3.06 / 1$ & M: $1.19 \mathrm{~F}: 1.40$ \\
\hline Gallbladder & 1.50 & 1.50 & 1.10 & 1.10 & $1 / 1$ & M: $0.73 \mathrm{~F}: 0.73$ \\
\hline
\end{tabular}

Table V. Alcohol consumption in Romania. Data compiled from the Global status report on alcohol and health- 2014 edition, Country profile: Romania, page: 232 [16].

\begin{tabular}{|l|l|l|l|l|}
\hline Alcohol consumption per capita, (15+years), (liters pure alcohol)/year & Average 1961 & Average 2003-2005 & Average 2008-2010 & Change \\
\hline Total & 5 & 12.8 & 14.4 & $\uparrow$ \\
\hline
\end{tabular}




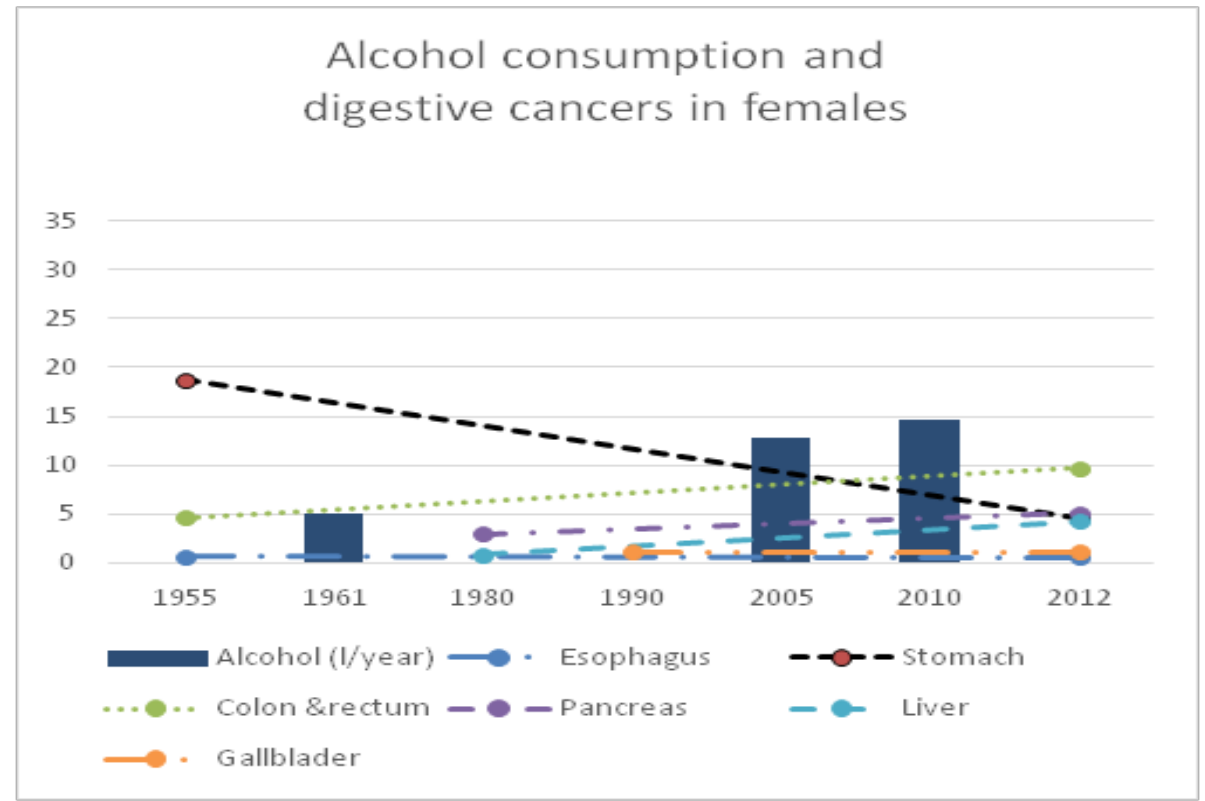

Figure 1.a. Alcohol consumption and digestive cancers in females.

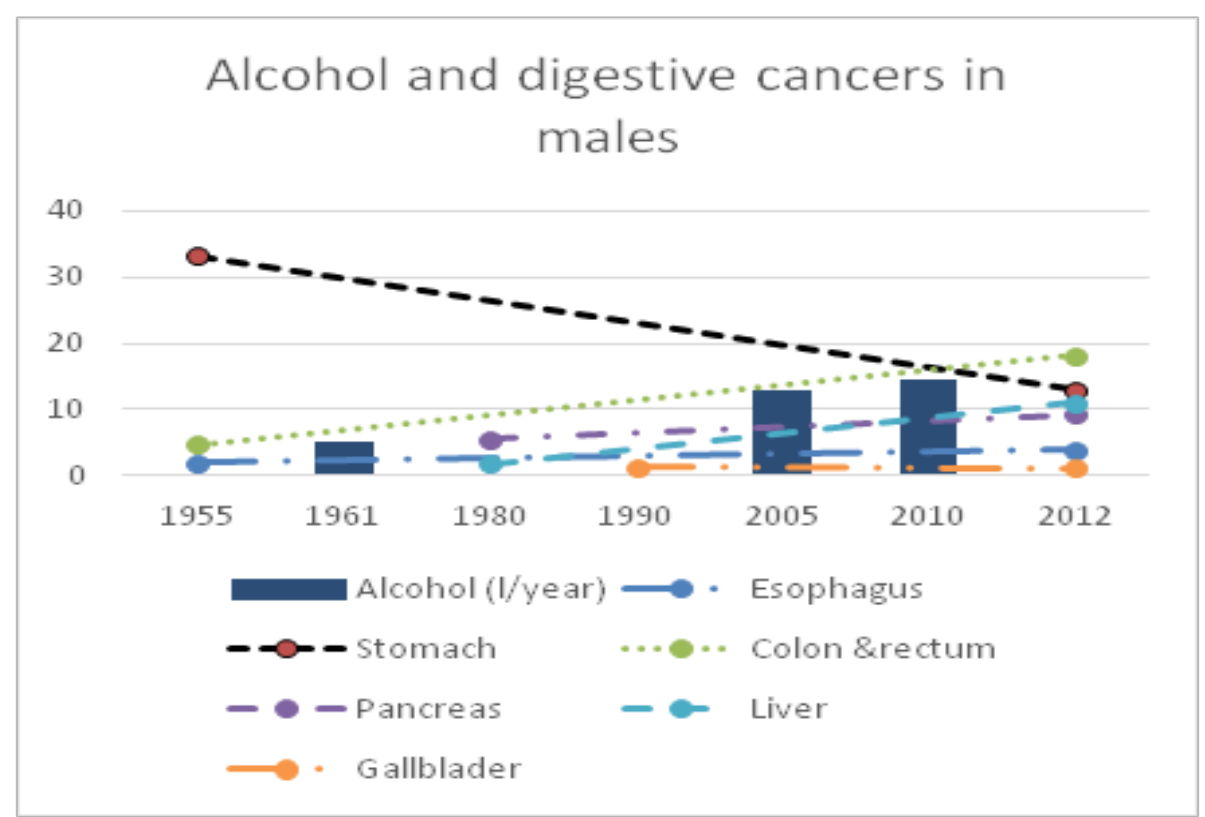

Figure 1.b. Alcohol consumption and digestive cancers in males.

The trend of increasing alcohol consumptions and the main 6 digestive cancers is displayed in Figure 1. In Figure 1.a the data of digestive cancers are for females, in Figure 1.b the data are for cancers in males. Of course, the alcohol consumption data cannot be broken according to the gender.

\section{Discussion}

Time trends 1955-2012 of digestive cancers in Romania

Our analysis compared the parallel time trend in alcohol consumption evolution and six most common digestive cancers. We aimed to detect a possible correlation between the increase in incidence of these neoplasia and the increase in alcohol consumption at populational level.

With regard to mortality, in the period of observation, an increasing trend was registered for the cancers of the esophagus in $\mathrm{M}$, and for the cancers of the colon and rectum (CRC), pancreas and liver in both sexes. A decreasing trend was registered in esophageal cancer in $\mathrm{F}$ and of gastric cancer (GC) in both genders. Gallbladder cancer has shown an apparently more stable status of mortality rate (Tables I, II). For cancers showing an increasing trend of mortality, the rate of increase was generally higher in males. For GC 
mortality, the decreasing trend was higher in F (Table II).

With regard to the incidence, between 2008-2012 an increasing trend was registered for the cancers of the esophagus (in M), GC (in M), CRC (in both sexes, but higher in M), pancreas (in F), and liver (in M). Cancers showing a stable evolution were esophageal cancer (in F), $\mathrm{GC}$ (in F), pancreatic cancer (in M), and liver cancer (in F). A declining trend was registered in gallbladder cancer (in both sexes) (Table III). Given the short period of the estimation of incidence rate, of four years, the data offered a possible epidemiologic orientation, and suggested the need of further surveillance. It is a problem of discussion if the increasing trends in incidence registered in recent times of some digestive cancers represent a real phenomenon, or the result of improved methods of diagnosis $[1-7,12]$.

As a result of the long time evolution of digestive cancers in our country, a new hierarchy was established as incidence and mortality rates (Tables I-III) [19-24]. In 2012, the most frequent recorded digestive malignancies as incidence were $\mathrm{CRC}, \mathrm{GC}$ and pancreatic cancer. As mortality, the most frequent malignancies were CRC, GC and liver cancer (Table III) [24].

The M:I ratio registered the highest rates in liver, pancreatic and esophageal cancer. The M:F ratio of incidence registered an increasing trend in cancers of the esophagus, stomach, colon and rectum and liver ((Table IV).

Between 2008-2012, GC registered a divergent evolution of mortality and incidence. The mortality continued to decrease in both sexes, but the incidence increased in $\mathrm{M}$ and appeared to be stabilized in $\mathrm{F}$ (Table III). The continuing decreasing rate of mortality could be attributed to an earlier diagnosis, due to the wide spread of endoscopy, and, eventually, better therapeutic approaches. The increasing of incidence can be related to an insufficient control of the risk factors in our area and the lack of screening. The incidence rates depend essentially on the control of the risk factors and screening, with a special emphasis on the known preneoplastic lesions and their approaches. The mortality of digestive cancers is mainly related to early diagnosis and treatment strategy and armamentarium, that registered substantial improvements, worldwide $[1-7,9,10,12]$.

CRC had the lowest M:I ratio, as compared to the other digestive cancers (Table IV). Our data on M:I ratio of colorectal cancer are comparable to the international records $[6,7]$. It could be related to a better diagnosis, favored by the use of colonoscopy, eventually earlier diagnosis and treatment efficacy. The strategy of CRC screening of persons beginning with 50 years of age and of endoscopic polypectomy of the adenomatous polyps of the colon, in order to prevent CRC, proved to be effective $[2,3,6,7,10]$, and is applied in our practical medical activity too. The $\mathrm{M} / \mathrm{F}$ ratio of mortality and incidence was the closest in all times (Tables I, IV), and that could suggest that $\mathrm{M}$ and $\mathrm{F}$ could share similar risk factors for this malignancy.
Liver cancer registered the highest and the more rapid rate of increase of mortality rates (Tables I, II). The mortality ratio exceeded the incidence rate in 2012, suggesting an under-diagnosis of the tumor (Table IV). This particular aspect was not unique to our areal. It could be related to the historical difficulties registered in liver cancer diagnosis [8]. An improvement in liver cancer diagnosis, eventually early detection, could be expected from dedicated screening strategies for cancer and risk factors $[8-10,12,13]$. The $\mathrm{M} / \mathrm{F}$ ratio of mortality slightly increased, and could suggest eventually that $\mathrm{M}$ share more risk factors for liver cancer.

Regarding pancreatic cancer, apart from its increasing trend and high mortality rate, a slight reduction in $\mathrm{M} / \mathrm{F}$ ratio was registered in our population. It could eventually suggest that the exposition to risk factors could become more similar.

\section{Time trends in alcohol consumption}

Our data show that in Romania too some cancers where alcohol consumption is not involved, i.e. gastric cancer, decreased in incidence in both genders. In females all the other digestive cancers have increase in parallel to the increased alcohol consumption, except the esophageal cancer. Alcohol is a risk factor for esophageal cancer but we may assume that the alcohol use in females was not so important to determine an elevation of esophageal cancer rate. With regard to the males, beside the decrease of gastric cancer and the constant prevalence of gallbladder cancer (which is not so common in males), the other cancer had a higher frequency in the interval associated with increased alcohol consumption. Our data confirm that alcohol is an oncogenic factor and the cancer prevention should include the prevention of alcohol abuse.

The trend in alcohol consumption is universal. Indeed, the worldwide consumption in 2010 was equal to 6.2 litres of pure alcohol consumed per year, per person aged 15 years or older, which translated into 13.5 grams of pure alcohol per day [16]. High-income countries had, apparently, the highest alcohol per capita consumption (APC) and the highest prevalence of heavy episodic drinking among drinkers [16]. The most prevalent tendency worldwide was an increase in recorded alcohol per capita consumption [16]. The problem of the recorded/unrecorded alcohol consumption was also under survey $[16,17]$. Europe was registered as the region with the highest level of alcohol consumption [17]. The total alcohol consumption per capita per year ( $\geq 15$ years of age) was near to 14 liters of pure alcohol in Romania in the period of estimation, second only to Lithuania, in Europe, in 2017 [17].

Alcohol consumption per capita registered a historical increase in Romania (as estimated by the Global report on alcohol and health - 2014 ed. Country profile: Romania, page:232) (Table V) [16]. Recorded/unrecorded alcohol consumption per capita $(15+$, in liters of pure alcohol) was estimated at average 8.8/4 in 2003-2005 and 
at 10.4/4 in 2008-2010) [16]. The increase in total alcohol consumption paralleled the increase in some of the digestive cancers in our country (Tables I, II) [19-24].

Alcohol has been shown to have many disease associations, acute and chronic. Depending on the dose and the frequency of use, the exposure to alcohol appeared to have an effect on cancer promotion, too [29-33]. The differences among individuals in the way alcohol is metabolized may stem from differences in genetics, nutrition, and factors such as the exposure to other carcinogens [29-33]. There may be different biological pathways, depending on the anatomical site [30]. The population of study might be important, given the genetic susceptibility, in general, and, in particular, the genotype of the enzymes that metabolize alcohol, of the consumer [30]. Many studies tried to answer to the question of alcohol consumption, as an etiological factor for cancer/digestive cancer, with nuances, independent etiologic risk factor, or cofactor, or coincidence.

Some epidemiologic associations have been found between alcohol consumption and the risk of cancer, at various sites. The mechanisms implicated could be related to the effects of acetaldehyde, the effects of alcohol on carcinogen metabolism, the interaction with nutritional factors, the effects of alcohol on hormone levels, the physical effects of alcohol on tissues, the additional effects related to the compounds found in alcoholic beverages [29-34], eventually the modulation of cancer stem cells and underlying cellular/molecular mechanisms [35]. With regard to the role in the carcinogenesis of the upper gastrointestinal tract, the microbial metabolism of alcohol to acetaldehyde might have a particular importance as well as the direct contact with alcoholic beverages [29,33,34]. The solvent properties of alcohol may enhance the effects of carcinogen exposure [33]. Alcohol effects on membrane fluidity may affect the tissue [34].

As regard to cancers, alcohol consumption has been identified as carcinogenic for the following cancer categories: cancer of the mouth, nasopharrynx, other pharynx and oropharynx, laryngeal cancer, oesophageal cancer, colon and rectum cancer, liver cancer and female breast cancer. In addition, alcohol consumption was considered to be a likely cause of pancreatic cancer too [16,17,29,30,36,37]. The higher the consumption, the greater the risk for these cancers [16-18,36,37]. A potential modifiable factor for cancer risk could be the alcohol control consumption [18]. Worldwide, $3.6 \%$ of all cancers $(5.2 \%$ in men and $1.7 \%$ in women) were attributable to alcohol drinking [36,37]. The Eastern Europe region appeared to experience the highest alcohol-attributable cancer burden, with 8.7 cancer deaths $/ 100000$ people (12.9 in men and 5.7 in women) [30]. In 2012 , about $5.9 \%$ of all global death $(7.6 \%$ among males and $4.0 \%$ among females) were attributable to alcohol, as well as $5.1 \%$ of the global burden of disease [16].

Alcohol consumption and digestive cancers/site

\section{Esophageal cancer and alcohol}

Esophageal cancer was recorded as the $8^{\text {th }}$ most common cancer worldwide, and the $6^{\text {th }}$ most common cause of death in the last epidemiologic global estimation in 2012. Incidence rates (ASRw) were 9.0/100,000 population in $\mathrm{M}$, and 3.1/100,000 population in F. Mortality rates were 7.7 , and 2.7 , respectively. These figures included both histological subtypes, esophageal adenocarcinoma (EAC) and esophageal squamous cell carcinoma (ESCC) [6]. Around $80 \%$ of the cases worldwide occurred in less developed regions. Global incidence rates were threefold higher in men, compared with women [6]. It had a very poor survival (M:I ratio of 0.88 ), and the geographical patterns of mortality were close to those of incidence [6]. Time trends of esophageal cancer have changed in western countries, where the EAC type registered a rapid increase in incidence, while the incidence of ESCC type has been relatively constant, or even declining [38].

Alcohol consumption appeared as a major risk factor for the ESCC type, and showed a dose-response risk [38]. The effects of alcohol were found to be stronger than tobacco, but the combined effect multiplied the risk [38]. Particular aspects were registered in some areas of the world, with the highest rates of the ESCC, like China and Iran, where alcohol and tobacco were not registered as major risk factors [38]. The relation of alcohol consumption with EAC type remained less characterized [38].

The synergy of alcohol consumption with other risk factors seemed to be important for the development of esophageal cancer [38,39]. Factors related to personal genetic susceptibility, and gene polymorphism of alcohol metabolizing enzymes of the consumer are non-modifiable risk factors. Other risk factors could be apparently modified. They include alcohol consumption (in terms of quantity, quality, the age of drinking initiation), and tobacco smoking. Particular aspects are related to infections agents (like HPV, Helicobacter pylori (Hp), oral microorganisms, nutritional deficiencies (like iron, folate, other micronutrients), medical conditions (like Barrett esophagus), obesity, medications (like antisecretory agents, and drugs that relax the gastroesophageal sphincter), that might be important [38].

\section{Gastric cancer and alcohol}

Gastric cancer (GC) registered a historical and universal trend to decrease [6,40-42]. The decreasing trend affected mainly the non-cardia type of GC. The cardia type of $\mathrm{GC}$ registered an increasing trend, or have been stable [40]. Gastric cancer was still the 5th most common malignancy worldwide (the 4 th in males and the 5 th in females), and represented $7 \%$ of the total new cancer cases and $9 \%$ of the total cancer death, in the last epidemiologic global estimation in 2012 [40]. The fatality rate was lower in countries with high levels of human development (M:I ratio, 0.65 ) as compared to countries at low or medium levels of human development (0.83) [40]. 
On the basis of most previous research, alcohol consumption seemed an unlikely cause of GC, although some results were partly contradictory [29,30,33,43]. Alcohol was suspected to be a greater risk factor for the cancer of the gastric cardia [44].

The fact that only $0.5 \%$ of the patients infected with Hp develop GC highly suggested the contribution of other risk factors [45]. A recent meta-analysis of 76 prospective cohort studies provided a comprehensive assessment of the association between diet, alcohol, and GC [45]. A concordant positive association between highsalt foods and GC was revealed. Elevated consumption of pickled vegetables, processes meat, salt fish, and salt were in relation to respectively $18 \%, 15 \%, 25 \%$, and $11 \%$ greater risk of GC. Alcohol drinking was associated with a $15 \%$ increased GC risk when the highest reported intake was compared with the lowest. Dose-response analysis indicated that the risk of GC was increased by $12 \%$ per $5 \mathrm{~g}$ /day increment of dietary salt intake or $5 \%$ per $10 \mathrm{~g} /$ day increment of alcohol consumption. A $100 \mathrm{~g}$ /day increment of fruit consumption was inversely associated with 5\% reduction of GC risk [45].

A positive association of GC risk was found only with heavy alcohol drinking [46]. An absence of association was found between alcohol drinking and esophageal and gastric cardia adenocarcinoma risk, even at higher doses of consumption [47]. Alcohol consumption and cigarette smoking may exert independent effects on the development of GC in high-risk populations for this malignancy, like China [48]. A link between alcohol consumption and the development of GC was supported from a study in the Lithuanian population, with up to 30 years follow-up [49]. Light drinking including even one alcoholic drink a day was associated with increased risk of esophageal, gastric and colorectal cancer in South Korean population [50].

Gastric cancer related to Hp infection was estimated at $71-95 \%$ of cases [51]. The global prevalence of $\mathrm{Hp}$ infection in general population was more than 50\% [52]. The prevalence of $\mathrm{Hp}$ in Eastern European adults was 70\% [52]. In Romania, a prevalence of Hp infection of $62 \%$ was recorded in the period of estimation [53]. In a large cohort of symptomatic population of study, Hp infection was recorded in $63.67 \%$ of the patients, higher in younger patients $(72.41 \%$ in patients aged less than 20 years old, and $66.22 \%$ in patients aged $20-29$ years old), in the period of the estimation [54]. One study, dedicated to MicroRNAs (miRNAS) polymorphisms related to GC concluded that the four miRNAS investigated showed no association with GC risk [55].

Four potential areas of intervention to prevent GC mortality were emphasized: Hp eradication, early detection through screening by endoscopy, surveillance of premalignant lesions, and life style modifications [56]. $\mathrm{Hp}$ eradication is part of the world strategy to prevent GC [57]. The reduction in alcohol consumption could help the strategy to prevent GC [16-18].

\section{Colorectal cancer and alcohol}

Colorectal cancer (CRC) represented $10 \%$ of the global cancer incidence burden in 2012 [6,58]. It was the 3rd most common cancer in men, and the 2nd in women $[6,58]$. Mortality was lower, and CRC was the 4th most common cause of death from cancer, worldwide [6,58]. Almost 55\% of the cases were registered in more developed regions [6]. Time trend appeared to stabilize or declining in countries that attained the highest levels of human development [58].

$\mathrm{CRC}$ was considered a lifestyle disease. It is a matter of debate of how the multiple suggested factors contribute to the risk. CRC was added to the list of alcohol attributable cancers $[16,17,29,58]$. An association between high alcohol consumption ( $\geq 30 \mathrm{~g}$ /day) and colorectal cancer was observed [59]. The antagonist effect of alcohol on folate metabolism was suggested as a possible mechanism $[15,59]$. A strong evidence for an association between alcohol intake and CCR was found in two recent metaanalysis, that included articles published before 2011 [60], and before 2014 (61]. The association of alcohol, as a risk factor, appeared to be evident for the proximal colon, distal colon and rectum [62]. The interaction of gut microbiota with diets and other lifestyle factors could affect the risk of CRC [63].

As regard to infections, papillomavirus (HPV) appeared as a major risk factor for perianal and anal cancers. For the cancers of the colon and rectum there existed no convincing evidence of the HPV involvement [13].

Pancreatic cancer and alcohol

Pancreatic cancer was estimated to be the 12th most common cancer in men, and the 11th most common cancer in women, as incidence, in the global 2012 record. In the same time, it was the 7th most common cause of death from cancer, in both sexes combined $[6,16]$. The majority of cases and death (55\%) were registered in developed regions [6]. It had a poor prognosis, with a M:I ratio of 0.98 [6]. The sex ratio was close to one [6].Trends of incidence and mortality rates in both sexes were rather stable over time [16].

Pancreatic cancer was added to the list of alcohol attributable cancers [16,17]. Alcohol could promote the development of pancreatic cancer through chronic high intake and via pancreatitis $[64,65]$. A synergistic effect with other risk factors was suggested (as metabolic risk factors and particular medical conditions, genetics, smoking, diet, working exposure) [65]. Only high alcohol intake appeared to be a significant risk factor for pancreatic cancer [66-69]. A case-control study suggested a non significant association between the risk of pancreatic cancer and alcohol, as either, the overall alcohol consumption or the type of alcohol consumed [70]. Given the histopathological diversity of pancreatic malignancies, the relation with the risk factors could be more complex $[64,66]$.

Liver cancer and alcohol

On the global scale, the primary liver cancer was a 
major contributor to both cancer incidence and mortality $[6,71,72]$. Liver cancer was the 5 th most common cancer in men and the 9th in women, but the 2nd most common cause of death from cancer worldwide, in the last global estimation from 2012 [6,72]. Given the high fatality of liver cancer (overall mortality-to-incidence ratio, 0.95), the geographical patterns and trends for mortality were very similar to those observed in incidence $[6,72]$.

A changing of incidence rates of hepatocellular carcinoma was registered in different areas of the world, apparently reflecting the changing distribution of the predisposing risk factors [71,72]. A time trend to increase of the primary liver cancer incidence was registered in many areas of the world, known as to have had a low incidence previously (Northern and Southern Europe, North and South America, Oceania, India, Israel). In contrast, the incidence rates manifested a time trend to decrease in areas known as to have had a high incidence (East Asian countries - Japan, China, Singapore, and in Spain) $[71,72]$. Liver cancer death rates (liver and intrahepatic bile duct cancer) registered an increasing trend in the USA at a faster pace than any other cancer [73].

Alcohol is a recognized risk factor for chronic liver disease, including liver cancer, by indirect and direct effects. Excessive consumption of alcohol was associated to the development of alcoholic hepatitis in $30-35 \%$ of consumers, and of cirrhosis in 10-15\% [74,75]. On the global scale, the etiology of hepatocellular carcinoma (HCC) was dominated by the hepatitis viruses B (HBV) and $\mathrm{C}(\mathrm{HCV})$ in more than $80 \%$ of the cases [76-79]. The contribution of alcohol to HCC risk was estimated at $15 \%$, higher in USA and Europe (20\%), as compared to Japan, Asia and Africa (10\%) [78]. In the period of the estimation, in the USA the proportion of HCC attributed to alcohol was $32 \%$, as compared to HBV (16\%) and HCV (22\%) [80]. In Italy, the proportions were $18 \%, 13 \%$ and $61 \%$, respectively, in the period of the estimation [81].

In Romania, $19.5 \%$ of cirrhosis had alcoholic etiology, $48.3 \%$ had viral etiology and $16.2 \%$ had double etiology, viral and alcoholic, in the period of the estimation [82]. The prevalence of both hepatitis viruses, $\mathrm{B}$ and $\mathrm{C}$, was high, in the period of the estimation [83-86]. This aspect was considered particular for our country, at the time [83]. HBV infection had a mean prevalence of 5.6\% [83] and the D genotype of HBV predominated [84]. HCV infection had a mean prevalence of 3.5\% [83], and the infection proved to be replicative in $90 \%$ of the HCV-positive subjects [85]. The genotype 1 of HCV was almost exclusively recorded in our area [86]. Delta virus infection (HDV) associated to HBV was registered in a higher proportion in patients with cirrhosis as compared to patients with chronic hepatitis $[87,88]$. Alcohol contribution to chronic hepatopathies was well documented in our country, and should continue, including $\mathrm{HCC}$, given the statistical data on alcohol consumption $[16,17]$. The fact that only $15-20 \%$ of alcohol consumers developed terminal cirrhosis emphasized the importance of other contributing risk factors [89].

\section{Gallbladder cancer and alcohol}

Gallbladder cancer (GBC) accounted for $1.3 \%$ of the total new cases, and $1.7 \%$ of all cancer death. About $65 \%$ of the cases were recorded in less developed regions. In was one of the digestive malignancies that registered a higher incidence in females $(\mathrm{M} / \mathrm{F}$ ratio of 0.76$)$ [6]. The most important risk factor was considered to be represented by gallstones. As only $1-3 \%$ of patients with gallstones developed gallbladder cancer, other risk factors were proposed to play a role [90]. GBC was the most common malignancy of the biliary tract, representing $80-95 \%$ of the biliary tract cancers worldwide [91]. The incidence of GBC registered an increase in USA in recent times, concurrent with the increases in cholecystectomy rates. This increase was attributable in part to improved histopathological detection of carcinoma in cholecystectomy specimens, as well as laparoscopic advances. GBC was detected with a frequency of $0.2 \%$ to $3 \%$ of all cholecystectomies. Although less prevalent, $\mathrm{GBC}$ had an extremely poor prognosis [92].

Data on alcohol consumption and GBC were unclear [93-96]. Some studies suggested an inverse association between alcohol intake and gallstone disease [93]. Other studies suggested that alcohol consuming elevated the risk of GBC in men, while its effect in women remained unclear [96]. Smoking appeared as a risk factor for GBC $[95,96]$, and gallstones [95].

The increasing trend of some digestive cancers and of alcohol consumption is not unique to our areal. The increasing trend of incidence registered by some digestive cancers in our country could have multiple etiological connotations, as in other areas of the world. It could be associated with the alcohol consumption too, taking into account an historical appearance parallel in their time trend.

\section{Conclusions}

The data derived from the IARC/WHO country statistics of cancers, historical and recent, and of $\mathrm{WHO} /$ UEG country statistics for alcohol consumption, revealed a parallel increase.

In terms of mortality, an increasing trend was registered for the cancers of the esophagus (in men), and the cancers of colon and rectum, pancreas and liver, in both sexes. In terms of incidence, an increasing trend was registered for the cancers of the esophagus (in men), gastric cancer (in men), colorectal cancer (in both sexes), pancreas (in women), and liver (in men). Alcohol consumption increased in the same period.

Given the parallel increase of some digestive cancers and alcohol consumption registered in our area, alcohol could represent more than a coincidence. Alcohol could be a real risk factor/cofactor promoting the development of preneoplasic lesions of the gastrointestinal tract, and, eventually, of digestive cancers. 


\section{References}

1. Bray F. Transition in human development and the global cancer burden. In World cancer report 2014; Stewart BW, Wild CP, Eds. Lyon: International Agency for Research on Cancer 2014, pp 54-68 2. Torre LA, Bray F, Siegel RL, Ferlay J, Lortet-Tieulent J, Jemal A. Global cancer statistics, 2012. CA Cancer J Clin. 2015;65:87108 .

3. Ferlay J, Steliarova-Foucher E, Lortet-Tieulent J, Rosso S, Coebergh JW, Comber H, et al. Cancer incidence and mortality patterns in Europe: estimaties for 40 countries in 2012. Eur J Cancer. 2013;49:1374-1403.

4. Ferlay J, Bray F, Pisani P, Parkin DM. Globocan 2000: cancer incidence, mortality and prevalence worldwide. IARC Cancer Base No.5. Lyon: IARC 2001.

5. Hu QD, Zhang Q, Chen W, Bai XI, Liang TB. Human development index is associated with mortality-to-incidence ratios of gastrointestinal cancers. World J Gastroenterol. 2013;19:52615270 .

6. Ferlay J, Soerjomataram I, Dikshit R, Eser S, Mathers C, Rebelo $\mathrm{M}$, et al. Cancer incidence and mortality worldwide: sources, methods and major patterns in GLOBOCAN 2012. Int J Cancer. 2015;136:E359-E386. doi: 10.1002/ijc.29210.

7. Forman D, Ferlay J. The global and regional burden of cancer. In: World cancer report 2014. Stewart BW, Wild CP (Eds.). Lyon: International Agency for Research on Cancer 2014, pp16-53. 8. Abou-Alfa G, Colombo M. Shaping the future management of hepatocellular carcinoma. Semin Liver Dis. 2013;33 Suppl 1:S20-S23.

9. von Karsa L, Qiao YL, Ramadas K, et al. Screening implementation. In: World cancer report 2014. Stewart BW, Wild CP (Eds.). Lyon: International Agency for Research on Cancer 2014, pp 330-336.

10. Smith RA, Manassaram-Baptiste D, Brooks D, Cokkinides V, Doroshenk M, Saslow D, et al. Cancer screening in the United States, 2014: a review of current American Cancer Society guidelines and current issues in cancer screening. CA Cancer J Clin. 2014;64:30-51.

11. Blot WJ, Tarone RE. Doll and Peto's quantitative estimates of cancer risks: holding generally true for 35 years. J Natl Cancer Inst. 2015;107(4. doi: 10.1093/jncl/djv044.

12. Kolonel LN, Wilkens LR. Migrant studies. In: Cancer epidemiology and prevention, 3rd ed. Schottenfeld D, Fraumeni JF Jr. (Eds). Oxford: University Press 2006: pp 189-201.

13. zur Hausen $H$. Infections causing human cancer. Weinheim: 2006 Wiley-VCH Verlag GmbH\&Co. KGaA, 2006.

14. Seitz KH, Mueller S. Alcohol and cancer: with special emphasis on the role of acetaldehyde and cytochrome P450 2E1. In: Biological basis of alcohol-induced cancer. Vassiliou V, Zakhari S, Hoek JB, Seitz KH (Eds.). Springer 2014: pp 59-70.

15. Willett WC. Diet and nutrition. In: Cancer epidemiology and prevention, 3rd ed. Schottenfeld D, Fraumeni JF, Jr. (Eds.). Oxford: University Press 2006: pp 405-421.

16. World Health Organisation, 2014. Global status rapport on alcohol and health - 2014 ed.. Available from: http://www.who. int/substance_abuse/publications/global_alcohol_report/en/.

17. United European Gastroenterology (UEG). Alcohol and digestive cancers across Europe: time for change, 2017. Available from: https://www.ueg.eu/news-details/article/alcohol-digestivecancers-time

18. LoConte NK, Brewster AM, Kaur JS, Merrill JK, Alberg AJ. Alcohol and cancer: a statement of the American Society of
Clinical Oncology. J Clin Oncol. 2018;36(1):83-93.

19. La Vecchia C, Lucchini F, Negri E, Boyle P, Maisonneuve P, Levi F. Trends of cancer mortality in Europe, 1955-1989: I, Digestive sites. Eur J Cancer. 1992;28:132-235.

20. Levi F, Lucchini F, La Vecchia C. Worldwide patterns of cancer mortality, 1985-89. Eur J Cancer Prev. 1994;3:109-143.

21. Levi F, La Vecchia C, Lucchini F, Negri E. Cancer mortality in Europe, 1990-92. Eur J Cancer Prev. 1995;4:389-417.

22. Levi F, Lucchini F, Negri E, Boyle P, La Vecchia C. Cancer mortality in Europe, 1990-1994, and an overview of trends from 1955 to 1994. Eur J Cancer. 1999;35:1477-1516.

23. Globocan 2008. Section of cancer information, Country Fast Stat. Romania. Available from: http://globocan.iarc.fr/Pages/fact sheets_cancer.aspx

24. Globocan 2012. Estimated cancer incidence, mortality and prevalence worldwide in 2012. Country Fast Stat. Romania. Available from: http://globocan.iarc.fr/Pages/fact_sheets_cancer. aspx

25. Valean S, Mircea PA, Oprea L, Frentiu D, Popescu G, Nagy G, et al. Trends of mortality rates from gastric cancer and colorectal cancer in Romania, 1955-2003. J Gastrointestin Liver Dis. 2006:15(2):111-115.

26. Vălean S, Armean P, Resteman S, Nagy G, Mureşan A, Mircea PA. Cancer mortality in Romania, 1955-2004. Digestive sites: esophagus, stomach, colon and rectum, pancreas, liver, gallbladder and biliary tree. J Gastrointestin Liver Dis. 2008;17(1):9-14.

27. Valean S. Cancere digestive. Epidemiologie si factori de risc, strategii de screening si supraveghere [Digestive cancers. Epidemiology and risk factors, screening and follow-up strategies]. Ed. Medicala Universitara Iuliu Hatieganu Cluj-Napoca, 2011.

28. Valean S, Acalovschi M, Diculescu M, Manuc M, Goldis A, Sfarti C, et al. Mortality of digestive cancers, 2012: international data and data from Romania. J Gastrointestin Liver Dis. 2015;24(4):507-514.

29. Marshall JR, Freudenheim J. Alcohol. In: Cancer epidemiology and prevention, 3rd ed; Schottenfeld D, Fraumeni JF, Jr, (Eds.). Oxford: University Press 2006: pp 243-258.

30. Rehm J, Shield K. Alcohol consumption. In: World cancer report 2014. Stewart BW, Wild CP (Eds.). IARC/WHO, Lyon 2014, pp 96-104.

31. Seitz HK, Stickel F. Molecular mechanisms of alcoholmediated carcinogenesis. Nat Rev Cancer. 2007;7:599-612.

32. Pöschl G, Seitz HK. Alcohol and cancer. Alcohol. 2004;39:155165.

33. Seitz HK, Pöschl G, Simanowski UA. Alcohol and cancer. Recent Dev Alcohol. 1998;14:67-95.

34. Simonotti P, Brusamolino N, Pellegrini P, Viani P, Clemente $\mathrm{G}$, Roggi C, et al. Evaluation of the effect of alcohol consumption on erythrocyte lipids and vitamins in health population. Alcohol Clin Exp Res. 1995;19:517-522.

35. Xu M, Luo J. Alcohol and cancer stem cells. Cancers (Basel). 2017 Nov 20;9(11). doi: 10.3390/cancers9110158.

36. Testino G, Borro P. Alcohol and gastrointestinal oncology. World J Gastrointest Oncol. 2010;2(8):322-325.

37. Boffetta P, Hashibe M, La Vecchia C, Zatonski W, Rehm J. The burden of cancer attributable to alcohol drinking. Int $\mathrm{J}$ Cancer. 2006;119:884-887.

38. Blot WJ, McLaughlin JK, Fraumeni JF,Jr. Esophageal cancer. In: Cancer epidemiology and prevention, 3rd ed. Schottenfeld D, Fraumeni JF, Jr (Eds.). Oxford: University Press 2006, pp 697-706. 39. Peng H, Chen H, Huo JR. Alcohol consumption and 
corresponding factors: a novel perspective on the risk of esophageal cancer (review). Oncology Letters 2016;11:32313239. doi: 10.3892/ol.2016.4401.

40. Carneiro F. Stomach cancer. In: World cancer report 2014. Stewart BW, Wild CP (Eds). IARC/WHO, Lyon 2014, pp 383-391. 41. Torre LA, Siegel RL, Ward EM, Jemal A. Global cancer incidence and mortality rates and trends--an update. Cancer Epidemiol Biomarker Prev. 2015;25(1):16-27.

42. Ferro A, Peleteiro B, Malvezzi M, Bosetti C, Bertuccio P, Levi F, et al. Worldwide trends in gastric cancer mortality (1980-2011), with predictions to 2015, and incidence by subtype. Eur J Cancer. 2014;50:1330-1344.

43. Sjödahl K, Lagergren J. Epidemiological aspects of gastric adenocarcinoma: are predictive diagnostics and targeted preventive measures possible? EPMA J. 2010;1:461-471.

44. Lagergren J, Bergström R, Lindgren A, Nyrén O. The role of tobacco, snuff and alcohol use in the aetiology of cancer of the oesophagus and gastric cardia. Int J Cancer. 2000;85:340-346.

45. Fang X, Wei J, He X, An P, Wang H, Jiang L, et al. Landscape of dietary factors associated with risk of gastric cancer: a systematic review and dose-response meta-analysis of prospective cohort studies. Eur J Cancer. 2015;51:2820-2832.

46. Tramacere I, Negri E, Pelucchi C, Bagnardi V, Rota M, Scotti $\mathrm{L}$, et al. A meta-analysis on alcohol drinking and gastric cancer risk. Ann Oncol. 2012;23:28-36.

47. Tramacere I, Pelucchi C, Bagnardi V, Rota M, Scotti L, Islami $\mathrm{F}$, et al. A meta-analysis on alcohol drinking and esophageal and gastric cardia adenocarcinoma risk. Ann Oncol. 2012;23:287-297. 48. Moy KA, Fan Y, Wang R, Gao YT, Yu MC, Yuan JM. Alcohol and tobacco use in relation to gastric cancer: a prospective study of men in Shanghai, China. Cancer Epidemiol Biomarkers Prev. 2010;19:2287-2297.

49. Everatt R, Tamosiunas A, Kuzmickiene I, Virviciute D, Radisauskas R, Reklaitiene R, et al. Alcohol consumption and risk of gastric cancer: a cohort study of men in Kaunas, Lithuania, with up to 30 years follow-up. BMC Cancer. 2012 Oct 15;12:475. doi: 10.1186/1471-2407-12-475.

50. Choi YJ, Lee DH, Han KD, Kim HS, Yoon H, Shin CM, et al. The relationship between drinking alcohol and esophageal, gastric or colorectal cancer: a nationwide population-based study of South Korea. PLoS One. 2017 Oct 3;12(10):e0185778. doi: 10.1371/journal.pone.0185778.

51. Malfertheiner P, Megraud F, O'Morain CA, Atherton J, Axon AT, Bazzoli F, et al. Management of Helicobacter pylori infection--the Maastricht IV/ Florence Consensus Report. Gut. 2012;61:646-664.

52. Hunt RH, Xiao SD, Megraud F, Leon-Barua R, Bazzoli F, van der Merwe S, et al. Helicobacter pylori in developing countries. World Gastroenterology Organisation Global Guideline. J Gastrointestin Liver Dis 2011;20(3):299-304.

53. Ciobanu L, Taulescu M, Dumitraşcu DL. Helicobacter pylori in Romania: Epidemiology, Diagnosis and Treatment. In: Buzas GM: Helicobacter pylori - A Worldwide Perspective. 2014, Bentham, pp 183-201.

54. Olar P, Mitrut P, Florou C, Malaescu GD, Predescu OI, Rogozea ML et al. Evaluation of Helicobacter pylori infection in patients with eso-gastro-duodenal pathology. Rom J Morphol Embryol. 2017;58(3):809-815.

55. Rogoveanu I, Burada F, Cucu MG, Vere CC, Ioana M, Cîmpeanu RA. Associaion of microRNA polymorphisms with the risk of gastric cancer in a Romanian population. J Gastrointestin Liver Dis. 2017;26(3):231-238.
56. Fock KM. Review article: the epidemiology and prevention of gastric cancer. Aliment Pharmacol Ther. 2014;40:250-260.

57. Malfertheiner P, Megraud F, O’Morain CA, Gisbert JP, Kuipers EJ, Axon AT, et al. Management of Helicobacter pylori infectionthe Maastricht V/Florence Consensus Report. Gut. 2017;66:6-30. 58. Bosman FT. Coloreactal cancer. In: World cancer report 2014. Stewart BW, Wild CP (Eds.). IARC/WHO, Lyon 2014, pp 392402.

59. Giovannucci E, Wu K. Cancers of the colon and rectum. In: Cancer epidemiology and prevention, 3rd ed. Schottenfeld D, Fraumeni JF, Jr (Eds.). Oxford: University Press 2006, pp 809-829. 60. Fedirko V, Tramacere I, Bagnardi V, Rota M, Scotti L, Islami $\mathrm{F}$, et al. Alcohol drinking and colorectal cancer risk: an overall and dose-response meta-analysis of published studies. Ann Oncol. 2011;22:1958-1972.

61. Wang Y, Duan H, Yang H, Lin J. A pooled analysis of alcohol intake and colorectal cancer. Int J Clin Exp Med. 2015;8(5):68786889.

62. Cho E, Smith-Warner SA, Ritz J, van den Brandt PA, Colditz GA, Folsom AR, et al. Alcohol intake and colorectal cancer: a pooled analysis of 8 cohort studies. Ann Intern Med. 2004; 140:603-613.

63. Tuan J, Chen YX. Dietary and lifestyle factors associated with colorectal cancer risk and interactions with microbiota: fiber, red or processed meat and alcoholic drinks. Gastrointest Tumors. 2016;3:17-24.

64. Hruban RH. Pancreatic cancer. In: World cancer report 2014. Stewart BW, Wild CP (Eds.). IARC/WHO, Lyon 2014, pp 413-421. 65. Anderson KE, Mack TM, Silverman DT. Cancer of the pancreas. In: Cancer epidemiology and prevention, 3rd ed. Schottenfeld D, Fraumeni JF, Jr (Eds.). Oxford: University Press 2006, pp 721-762.

66. Korc M, Jeon CY, Edderkaoui M, Pandol SJ, Petrov MS; Consortium for the Study of Chronic Pancreatitis, Diabetes, and Pancreatic Cancer (CPDPC). Tobacco and alcohol as risk factors for pancreatic cancer. Best Pract Res Clinl Gastroenterol. 2017;31(5):529-536.

67. Wang YT, Gou YW, Jin WW, Xiao M, Fang HY. Association between alcohol intake and the risk of pancreatic cancer: a doseresponse meta-analysis of cohort studies. BMC Cancer. 2016 Mar 12;16:212. doi: 10.1186/s12885-016-2241-1.

68. Tramacere I, Scotti L, Jenab M, Bagnardi V, Bellocco R, Rota $\mathrm{M}$, et al. Alcohol drinking and pancreatic cancer risk: a metaanalysis of the dose-risk relation. Int J Cancer. 2010;126:14741486.

69. Gupta S, Wang F, Holly EA, Bracci PM. Risk of pancreatic cancer by alcohol dose, duration, and pattern of consumption, including binge drinking: a population-based study. Cancer Causes Control. 2010;21:1047-1059.

70. Yellow W, Bamlet WR, Oberg AL, Anderson KE, Olson JE, Sinha R, et al. Association between alcohol consumption, folate intake, and risk of pancreatic cancer: a case-control study. Nutrients. 2017 May 1;9(5). doi: 10.3390/nu9050448.

71. McGlynn KA, London WT. The global epidemiology of hepatocellular carcinoma: present and future. Clin Liver Dis. 2011;15(2):223-243, doi:10.1016/jcld.2011.03.006-[2].

72. Theise ND. Liver cancer. In: World cancer report 2014; Stewart BW, Wild CP (Eds.). International Agency for research on Cancer, Lyon, 2014, pp 403-412.

73. Islami F, Miller KD, Siegel RL, Fedewa SA, Ward EM, Jemal A. Disparities in liver cancer occurrence in the United States by race/ethnicity and state. CA Cancer J Clin. 2017;67(4):273-289. 
74. Seitz HK. Alcoholic liver disease. Risk factors and treatment options 2012. Romanian-German Symposium of Gastroenterology. Cluj-Napoca, March 22-23, 2012.

75. Niederau C. Alcoholic hepatitis. In: Hepatology - a clinical textbook. 2nd ed. Mauss S, Berg T, Rockstroh J, Sarrazin C, Wedemeyer H. (Eds.). Dusseldorf: Flying Publisher, 2010, pp 467-487.

76. Ferenci P, Fried M, Labrecque D, et al. WGO Global Guideline. Hepatocellular carcinoma (HCC): a global perspective. World Gastroenterology Organization 2009.

77. Bruix J, Sherman M; Practice Guidelines Committee, American Association for the Study of Liver Diseases. Management of hepatocellular carcinoma. Hepatology. 2005;42:1208-1236.

78. European Association For The Study Of The Liver1; European Organisation For Research And Treatment Of Cancer. EASL-EORTC clinical practice guidelines: management of hepatocellular carcinoma. J Hepatol. 2012;56:908-943.

79. Verslype C, Rosmorduc O, Rougier P; ESMO Guidelines Working Group. Hepatocellular carcinoma: ESMO-ESDO Clinical Practice Guidelines for diagnosis, treatment and followup. Ann Oncol. 2012;23 Suppl 7:vii41-vii48.

80. Gao J, Xie L, Yang WS, Zhang W, Gao S, Wang J, et al. Risk factors of hepatocellular carcinoma--current status and perspectives. Asian Pac J Cancer Prev. 2012;13:743-752.

81. Franceschi S, Montella M, Polesel J, La Vecchia C, Crispo A, Dal Maso L, et al. Hepatitis viruses, alcohol, and tobacco in the etiology of hepatocellular carcinoma in Italy. Cancer Epidemiol Biomarkers Prev. 2006;15(4):683-689.

82. Grigorescu M, Radu C, Pascu O, et al. Etiological profile of chronic hepatitis and liver cirrhosis in Romania. A multicenter study. Rom J Gastroenterol 2001;10:199-204.

83. ECDC Technical Report. Hepatitis $B$ and $C$ in EU neighbourhood : prevalence, burden of disease and screening policies, 2010. Available from: www.ecdc.europa.eu

84. Deterding K, Constantinescu I, Nedelcu FD, Gervain J, Nemecek V, Srtunecky O, et al. Prevalence of HBV genotypes in Central and Eastern Europe. J Med Virol. 2008;80(10):17071711.

85. Gheorghe L, Csiki IE, Iacob S, Gheorghe C, Smira G, Regep $\mathrm{L}$. The prevalence and risk factors of hepatitis $\mathrm{C}$ virus infection in adult population in Romania: a nationwide survey 2006-2008. J
Gastrointestin Liver Dis. 2010;19(4):373-379.

86. Grigorescu M; Romanian Society of Gastroenterology and Hepatology. HCV genotype 1 is almost exclusively present in Romanian patients with chronic hepatitis C. J Gastrointestin Liver Dis. 2009;18(1):45-50.

87. Grigorescu M, Pascu O, Acalovschi M, Radu C. What is the real prevalence of the $\mathrm{D}$ virus infection in chronic hepatitis and liver cirrhosis in Romania? Rom J Gastroenterol. 2003;12(3):179182.

88. Gheorghe L, Csiki IE, Iacob S, Gheorghe C, Trifan A, Grigorescu M, et al. Heptitis Delta virus infection in Romania: prevalence and risk factors. J Gastrointestin Liver Dis. 2015;24(4):413-421.

89. Tuma DJ, Sorrell M. Alcohol and alcoholic liver disease. Seminars in liver diseases 2004;24(3):215.

90. Randi G, Franceschi S, La Vecchia C. Gallbladder cancer worldwide: geographical distribution and risk factors. Int $\mathrm{J}$ Cancer. 2006;118:1591-1602.

91. Hundal R, Shaffer EA. Gallbladder cancer: epidemiology and outcome. Clin Epidemiol. 2014;6:99-109.

92. Lau CSM, Zywot A, Mahendraraj K, Chamberlain RS. Gallbladder Carcinoma in the United States: A Population Based Clinical Outcomes Study Involving 22,343 Patients from the Surveillance, Epidemiology, and End Result Database (1973-2013). HPB Surg. 2017;2017:1532835. doi: $10.1155 / 2017 / 1532835$.

93. Leitzmann MF, Giovannucci EL, Stampfer MJ, Spiegelman D, Colditz GA, Willett WC, et al. Prospective study of alcohol consumption patterns in relation to symptomatic gallstone disease in men. Alcohol Clin Exp Res. 1999;23(5):835-841.

94. Lazcano-Ponce EC, Miquel JF, Muñoz N, Herrero R, Ferrecio C, Wistuba II, et al. Epidemiology and molecular pathology of gallbladder cancer. CA Cancer J Clin. 2001;51:349-364.

95. Hsing AW, Rashid A, Devesa SS, Fraumeni JF, Jr. Biliary tract cancer. In: Cancer epidemiology and prevention, 3rd ed; Schottenfeld D, Fraumeni JF, Jr (Eds.). Oxford: University Press 2006, pp 787-800.

96. Yagyu K, Kikuchi S, Obata Y, Lin Y, Ishibashi T, Kurosawa $\mathrm{M}$, et al. Cigarette smoking, alcohol drinking and the risk of gallbladder cancer death: a prospective cohort study in Japan. Int J Cancer. 2008;122:924-929. 